\title{
Os registros da experiência da criança na linguagem: 0 ato enunciativo de transcrição
}

\section{The recording of children's experience in language: the enunciative act of transcription}

\author{
Marlete Sandra Diedrich \\ http://orcid.org/0000-0002-9177-089X \\ Universidade de Passo Fundo \\ marlete@upf.br
}

Resumo: Este artigo aborda a atividade de transcrição envolvida nas pesquisas com fatos de linguagem de criança nas quais os arranjos vocais ganham destaque na análise. Tem por objetivo refletir acerca da atividade de transcrição de fatos de linguagem da criança, a partir de uma perspectiva enunciativa aquisicional. A especificidade desse ponto de vista reside no seguinte aspecto: nos fatos de linguagem da criança marcados por arranjos vocais, o gesto interpretativo do transcritor precisa recair sobre formas discursivas nem sempre coincidentes às da língua, característica da aquisição da linguagem, além de dar conta do registro por escrito de aspectos advindos da manifestação vocal da língua. Com base em princípios derivados dos estudos do linguista Émile Benveniste sobre enunciação, entende-se a transcrição como um ato enunciativo, o que coloca em destaque a figura do transcritor e a relação de interpretância que este estabelece com os fatos analisados.

Palavras-chave: transcrição; enunciação; linguagem da criança.

Abstract: This paper discusses the transcription activity in research on child language in which vocal arrangements are highlighted in the analysis. It aims to reflect on the transcription activity of child 
language from an enunciative perspective of language acquisition. The specificity of this view lies in the following aspect: given child language phenomena marked by vocal arrangements, the interpretative gesture of the transcriber must fall on discursive forms, which do not always coincide with standard language forms This is characteristic of language acquisition and the transcriber's interpretative gesture allows for the written registration of oral language aspects. Based on principles stemming from Emile Benveniste's studies on enunciation, transcription is, therefore, understood as an enunciative act, that highlights the role of the transcriber and the relation of interpretation henceforth established with the recorded phenomena.

Keywords: transcription; enunciation; child's language.

Recebido em: 6 de julho de 2016. Aprovado em: 15 de julho de 2016.

\section{0 percurso traçado}

Partimos do princípio de que a atividade de transcrição envolvida nas pesquisas com fatos de linguagem de criança nas quais os arranjos vocais ganham destaque na análise envolvem um trabalho de transcrição caracterizado por determinadas particularidades. Por isso, ocupamo-nos em descrever as singularidades dessa atividade e analisar algumas das escolhas de transcrição realizadas pelo pesquisador em determinados trabalhos. A especificidade desse ponto de vista reside no seguinte aspecto: nos fatos de linguagem da criança marcados por arranjos vocais, o gesto interpretativo do transcritor precisa recair sobre formas discursivas nem sempre coincidentes às da língua, característica da aquisição da linguagem, além de dar conta do registro por escrito de aspectos advindos da manifestação vocal da língua. Para tratarmos dessa questão, lançamos, inicialmente, algumas problemáticas enunciativas que iluminam a discussão, pautados nos estudos de Émile Benveniste, autor no qual buscamos fundamentação para nossa jornada investigativa. Essas problemáticas apontam para um aspecto fundamental no trabalho do transcritor: as relações de interpretância mobilizadas na transcrição, as quais caracterizam o ato do pesquisador transcritor. Tais relações são 
evidenciadas em uma pesquisa com fatos de linguagem de criança por nós empreendida e cujas decisões em torno da transcrição ilustram bem nosso pensamento. Por fim, nossa reflexão sugere a possibilidade de novos olhares para o tema da transcrição de fatos dessa natureza.

\section{Problemáticas enunciativas envolvidas na transcrição}

Após alguns estudos e pesquisas acerca da linguagem da criança, em especial, dos aspectos vocais da língua na experiência da criança, percebemos que, numa investigação na área da Aquisição da Linguagem, os pesquisadores em geral necessitam buscar e registrar dados de fala da criança. Neste artigo, ao refletirmos sobre esse trabalho de registro do pesquisador, assumimos o ponto de vista de uma abordagem enunciativa aquisicional, a qual, na perspectiva de Silva (2009, p. 158), envolve "considerar os dados de aquisição num quadro de singularidade, no qual está implicada a relação do sujeito com o ‘outro' e com a língua a cada ato enunciativo". Os "dados" referidos por Silva (2009) são entendidos por nós como "fatos de linguagem", denominação que assumimos no lugar do uso da palavra "dados", a qual é comumente percebida em pesquisas dessa natureza. Isso porque, conforme discutiremos neste artigo, não vemos tais fatos como uma realidade pronta, dada, já que há um trabalho intenso de interpretação efetuado pelo pesquisador. São justamente as especificidades desse trabalho que, acreditamos, caracterizam o momento de transcrição e de análise dos fatos de linguagem estudados. Pensar sobre esse trabalho revela-se tema pertinente e necessário no universo da pesquisa científica.

Neste artigo, temos, assim, o objetivo de refletir acerca da atividade de transcrição de fatos de linguagem da criança, a partir de uma perspectiva enunciativa aquisicional. Fazemos isso com a ciência de que outros pesquisadores já trataram do tema da transcrição, como Flores (2006); Silva (2009), Surreaux (2014), entre outros. Certamente, muitos deles, como os três citados, são trabalhos que nos motivam a afirmar o que aqui trazemos e que iluminam a especificidade de nossa discussão. No entanto, não estamos apenas repetindo o já dito; nosso interesse de pesquisa é renovado, uma vez que nossa reflexão procura dar conta de aspectos da transcrição em pesquisas com fatos de linguagem de criança nas quais os arranjos vocais ganham destaque na análise. 
Entendemos, portanto, que o tratamento dado pelo transcritor aos registros dos arranjos vocais merece reflexão, uma vez que ele envolve, entre outras complexidades, a passagem do oral para o escrito, movimento que exige do transcritor a tomada de decisões acerca de como lidar com esse registro. Além disso, ao se tratar de fatos de linguagem da criança, uma outra dimensão é vislumbrada: a da aquisição da linguagem, entendida como uma experiência de significação, a qual exige um olhar específico do pesquisador, uma vez que não se trata de comparar essa experiência à experiência do adulto, mas de buscar entender o mover da criança no mundo do adulto via linguagem e buscar recursos de registro dessa experiência.

Paradoxalmente, sabemos que uma experiência na linguagem não poderá jamais ser registrada por completo, pois ela extrapola o âmbito do registro e se constitui na efemeridade do aqui e do agora de cada enunciação. Além disso, a atividade de transcrição, sem dúvida, é altamente influenciada pelo olhar interpretativo do transcritor sobre o fato a ser transcrito, uma vez que esta etapa da investigação leva o pesquisador a uma tomada de decisões frente aos fatos. Por essa razão, a transcrição é entendida neste artigo como um ato subjetivo, uma nova enunciação, marcada pelo agir do transcritor:

O transcritor, ao se apropriar do aparelho formal de enunciação, institui-se como locutor para produzir referências e sentidos no discurso transcrito. Tais sentidos construídos pelo locutor-transcritor para o observável instanciam o teórico não presente na linearidade do discurso transcrito, mas constitutivo dele, já que está presente no transcritor um ponto de vista teórico a priori que prevê produção de referências, através de marcas específicas e comentários para elementos verbais e nãoverbais contidos na cena. Esse ponto de vista teórico é criador do objeto transcrito. (SILVA; ENDRUWEIT , 2011, p. 250)

Como uma nova enunciação, as marcas da transcrição, no dizer de Silva e Surreaux (2011, p. 294), "instanciam o caráter de intersubjetividade da enunciação (intersubjetividade na medida em que envolve um eu transcrevendo para um tu)", uma vez que o transcritor almeja constituir um dado como um fato que foi apreendido e que se revela possível de ser analisado para um outro ou para ele próprio. 
Entende-se, assim, com base em Silva (2009), que a transcrição dos fatos de linguagem já representa uma etapa de análise.

O pesquisador, ao trabalhar com a linguagem de crianças em aquisição de linguagem, em geral, trabalha com elementos vocais, os quais são compreendidos neste artigo como arranjos vocais. Ao pensar a atividade de transcrição, percebe-se que também o transcritor desempenha o papel de percepção da emissão vocal do locutor, já que ele precisa acessar a experiência do falante na comunicação de significados. O transcritor assume, dessa forma, em relação ao locutor, o papel do outro, do $t u$, na enunciação, uma vez que, desde o momento em que o locutor assim se declara e assume a língua, "ele implanta o outro diante de si" (BENVENISTE, 1970/1989, p. 84, grifo do autor), com todas as implicações que esse papel traz, o que faz o pesquisador pensar com maior rigor ainda o método de transcrição. Assim, é difícil adotar um modelo de transcrição único ou definido previamente, já que o pesquisador se depara com as singularidades de cada ato, de cada fato, o que exige uma decisão de registro sempre renovada. Para tanto, lembramos Flores (2006, p. 74) quando diz que "Cada transcrição é sempre única, singular e não linearmente extensível: é o efêmero". De fato, a singularidade do ato enunciativo move a singularidade da transcrição, dada a experiência renovada vivida a cada situação.

Além disso, há a implicação da complexidade dos fatos com os quais se trabalha. Em pesquisas cujo foco de investigação são as especificidades da realização vocal da enunciação na experiência da criança na linguagem, por exemplo, o pesquisador é levado a observar fenômenos de realização fônica, nos quais os arranjos vocais, em sua materialidade, mobilizam sentidos particulares das formas linguísticas, mas também exigem que se observem a gesticulação, os movimentos corporais e faciais, uma vez que esses recursos também afetam o sentido na situação enunciativa. Em alguns casos, as formas da língua ainda não se encontram completas para a criança, e o sentido é garantido tão somente pela mobilização da realização vocal na particularidade de cada enunciação, na relação de emissão e percepção de cada ato. O método de transcrição escolhido, frente a essa complexidade de informações, precisa contemplar todos esses registros e é com esse intuito que o pesquisador transcritor mobiliza esforços em sua investigação. No entanto, temos certeza de que, independente do método de transcrição escolhido, as pesquisas conseguem apenas uma imagem representativa 
do fenômeno da enunciação falada e jamais se conseguirá resgatar toda a sua complexidade.

Acerca disso, Silva e Surreaux (2011) trabalham com a ideia de que na transcrição perde-se a voz, restando um efeito da escuta do transcritor. Esse fato assume grande importância em trabalhos de investigação que se voltam para os elementos vocais, uma vez que se faz necessário buscar recursos na transcrição para representar os arranjos vocais específicos de cada enunciação. Além disso, sabe-se que a transcrição não é uma operação mecânica, mas uma tentativa de reconstituição das condições de produção do ato enunciativo. Nesse sentido, lembramos que

a oralidade excede os limites da transcrição. A verificação do dado oral transcrito nas pesquisas revela a heterogeneidade de sua constituição, pois ora o discurso transcrito aparece com muitas marcas específicas, ora com poucas marcas, ora com comentários do transcritor e ora sem comentário do transcritor. (SILVA; ENDRUWEIT, 2011, p. 248).

Frente a isso, mais uma vez afirmamos que a transcrição se revela um ato interpretativo do pesquisador. Silva (2009), com base em Rey-Debove (1996), afirma que na atividade da transcrição há sempre um "resto", uma vez que não se pode passar diretamente de um sistema para outro. E aí deparamo-nos com o conceito de interpretância proposto por Benveniste (1969/1989), segundo o qual a relação que se estabelece entre sistemas é de sistema interpretante e de sistema interpretado.

Dadas essas problemáticas todas que envolvem a questão, propomo-nos a discutir tais aspectos sob as luzes de princípios enunciativos, os quais se revelam capazes de esclarecer o ato de transcrição e explicitar a relação de interpretância mobilizada pelo pesquisador transcritor. Acerca disso, ocupamo-nos na sequência.

\section{As relações de interpretância e a transcrição}

Em Semiologia da língua, Benveniste convoca à discussão as relações entre sistemas de signos, tema central para a atividade de transcrição. Nesse texto, o linguista (1969/1989, p. 51) mostra, a partir da ideia de que "utilizamos concorrentemente e a cada instante vários sistemas de signos", um elenco de signos que marcam a vida 
social de todo indivíduo. Nesse elenco, Benveniste (1969/1989, p. 51) apresenta: "em primeiro lugar os signos da linguagem, que são aqueles cuja aquisição começa mais cedo, com o início da vida consciente; os signos da escrita;..." e segue sua lista de variados signos que marcam a existência humana e sua vida em sociedade. O que une todos os sistemas a que se refere e ainda os outros tantos existentes, segundo o autor, é a propriedade de significância de todos eles e a sua composição em signos, unidades de significância. $\mathrm{O}$ autor depreende dois princípios que dizem respeito às relações entre sistemas semióticos. O primeiro deles é o princípio de não redundância entre sistemas, ou seja, não há sinonímia entre sistemas semióticos de base diferente. Deparamo-nos aqui com o que poderia ser um limitador para nossa atividade de transcrição: se, de fato, não se pode "dizer a mesma coisa"” (BENVENISTE, 1969/1989, p. 53) pelo sistema oral e pelo sistema escrito, a transcrição a que nos dedicamos nesta investigação seria inatingível, uma vez que "O homem não dispõe de vários sistemas distintos para a MESMA relação de significação.” (BENVENISTE, 1969/1989, p. 53, grifo do autor). No entanto, salientamos que o argumento de Benveniste diz respeito a "sistemas semióticos de base diferente", o que não se presta ao exame das relações entre sistema oral e sistema escrito, os quais encontram na língua sua mesma base. Como segundo princípio que rege as relações entre sistemas semióticos, o autor afirma que um mesmo signo pode fazer parte de dois sistemas sem caracterizar sinonímia, uma vez que o valor do signo só pode ser definido no sistema que o integra. Há, no entanto, entre os sistemas uma relação de natureza semiótica, "determinada primeiramente pela ação de um mesmo meio cultural, que de uma maneira ou de outra produz e alimenta a todos os sistemas que lhe são próprios". Essa relação aponta para a possibilidade ou impossibilidade de autointerpretação, responsável pela existência de sistemas interpretantes e sistemas interpretados. E é justamente por essa condição que "a língua ocupa uma situação particular no universo dos sistemas de signos": ela será sempre o sistema interpretante de todos os demais sistemas, inclusive dela mesma, pois "a língua pode, em princípio, tudo categorizar e interpretar, inclusive ela mesma” (BENVENISTE, 1969/1989, p. 54; 55; 62).

Encontramos ainda nos trabalhos de Benveniste um exame particular do sistema de escrita nas notas manuscritas deixadas pelo linguista e organizadas por Coquet e Fenoglio em Dernières Leçons (BENVENISTE, 2012) e em cuja tradução, apresentada em Últimas aulas 
no Collège de France, publicada no Brasil (BENVENISTE, 2014), nos apoiamos. Na obra organizada, encontramos, no capítulo 2, A língua e a escrita, a discussão já referida em Semiologia da língua acerca da escrita e do exame particular que ela mereceria. A partir de notas manuscritas de Benveniste, os organizadores apresentam a visão do linguista acerca dessa relação específica. Trata-se de um complexo raciocínio acerca da escrita, apresentando-a como "uma imagem da língua":

A atividade completa na qual o locutor está engajado, esse comportamento tanto gestual quanto fonoacústico, essa participação do outro, de todos os outros, da totalidade dos parceiros possíveis nessa manifestação individual e coletiva, tudo isso é substituído por signos traçados à mão. (BENVENISTE, 2014, p. 129-130).

Não podemos deixar de identificar a relação possível de se estabelecer entre o trabalho de transcrição a que nos referimos e a descrição apresentada por Benveniste: de fato, o transcritor tem a pretensão de substituir por signos traçados à mão toda a completude da atividade de enunciação, a qual envolve os arranjos vocais na experiência da criança na linguagem.

O autor (2014), em seus manuscritos, aprofunda suas ideias acerca da escrita, trazendo outras revelações sobre a questão: a escrita é vista pelo autor como uma forma secundária da fala. Essa visão benvenistiana acerca da relação fala e escrita baseia-se no princípio de que a escrita é uma autossemiotização da língua, uma vez que ela comporta as duas propriedades específicas do discurso: semiótica e semântica. A partir da ideia de sistema interpretante e sistema interpretado, Benveniste (2014, p. 79) afirma que a escrita permite à língua se autossemiotizar. Trata-se da "fala convertida pela mão em signos falantes", uma vez que a relação estabelecida pelo aspecto vocal da língua por meio da escuta é retransmitida pelo sistema da escrita, o qual envolve o mecanismo interpretante do traçado das letras.

Entendemos que é essa a relação que o pesquisador vive na transcrição, ao passar os fatos da linguagem em sua manifestação falada, expressão natural do corpus a ser investigado, para a manifestação escrita, registro desse corpus: o papel do pesquisador, na função de transcritor, é, inicialmente, o papel de percepção das emissões vocais, com toda a complexidade gestual e corporal que caracteriza as vocalizações 
com as quais ele trabalha. Na sequência, o mesmo transcritor passa à atividade de registro escrito dessas emissões vocais, o qual precisa ser lido pelas demais pessoas, a fim de que, de fato, a pesquisa possa se dar a conhecer. $\mathrm{Na}$ base desses dois processos, está a língua, o que nos leva a entender as relações possíveis entre a fala e a escrita. Para isso, retornamos ao Semiologia da língua, uma vez que é nesse texto que encontramos as possibilidades de relações entre sistemas semióticos. Para Benveniste (1969/1989), um sistema semiológico caracteriza-se pelo seu modo operatório, pelo seu domínio de validade, pela natureza e pelo número de signos, assim como pelo tipo de funcionamento. Quando pensamos na passagem do oral para o escrito, faz-se necessário que o modo operatório se modifique de auditivo para visual, o que implica um esforço grande do transcritor para buscar marcar os fenômenos característicos do sistema falado no sistema escrito ou iconográfico. Também os domínios de validade são diferentes: o falado é reconhecido na efemeridade de sua realização, enquanto o registro escrito se mantém válido no papel enquanto durar o registro; acreditamos que em relação à natureza, linguística, não há modificações, mas quanto ao número dos signos, sim, assim como quanto ao seu funcionamento: no falado, os fonemas funcionam em relação de oposição, enquanto no registro escrito esse papel cabe às letras e aos sinais iconográficos em geral. No entanto, esses sistemas mantêm relações entre si, as quais marcam o trabalho de transcrição. Essas relações, baseadas na classificação de Benveniste (1969/1989, p. 61), atestam o que afirmou o linguista: "Um sistema pode engendrar outro sistema".

Acreditamos que há, sim, entre eles, uma relação de engendramento, uma vez que se trata de "dois sistemas distintos e contemporâneos, mas de mesma natureza” (BENVENISTE, 1969/1989, p. 61), entendida por nós como a natureza linguística. E, por fim, a relação mais evidente: a relação de interpretância, referida por Benveniste nas notas traduzidas em Últimas aulas no Collège de France (2014), reveladora da capacidade de autossemiotização da língua. A escrita é, para Benveniste, a prova de que a língua se autossemiotiza, de que ela pode interpretar a si mesma. Ou seja, o que temos, essencialmente, tanto na escrita quanto na fala, são as propriedades da língua. No caso específico da transcrição, transposição da fala para a escrita, cumpre-se o que afirmou Benveniste (2014, p. 179): "Não teria sido possível refletir acerca da análise da linguagem falada se não se dispusesse dessa ‘linguagem visível' que é a escrita.” De 
fato, o pesquisador da linguagem, para tomar consciência dos arranjos vocais que marcam os dados em questão, lança mão de recursos da escrita que se "revezam" em relação aos arranjos vocais mobilizados no discurso, realizando a "fala transferida" mencionada pelo linguista (BENVENISTE, 2014, p. 179).

Para melhor ilustrarmos a questão, trazemos, a seguir, uma experiência de transcrição por nós vivenciada, na qual destacamos as relações de interpretância no ato enunciativo marcado pela relação de emissão e percepção de arranjos vocais mobilizados por uma criança de dois anos de idade.

\section{Uma experiência}

Como já deixamos claro neste artigo, entendemos que um trabalho na perspectiva enunciativa aquisicional leva o pesquisador transcritor a assumir determinadas normas de transcrição específicas para o aqui e o agora por ele vivenciado em relação aos fatos de linguagem a serem analisados, o que o impede, em geral, de se apropriar de normas já definidas em outras pesquisas. Isso porque o ato se renova a cada fato enunciativo, levando também o pesquisador transcritor, em seu gesto de interpretação do dizer do outro, a renovar suas escolhas realizadas na transcrição.

Para melhor discutirmos essa questão, apresentamos dois recortes enunciativos, os quais fizeram parte do corpus de nossa pesquisa de doutorado (DIEDRICH, 2015), disponível em http://hdl.handle. net/10183/130026, para, a partir dos fatos enunciativos nele revelados, podermos refletir sobre as escolhas de transcrição realizadas e o que elas nos dizem acerca das relações de interpretância vivenciadas pelo pesquisador transcritor.

É importante ainda destacar que nesses registros contamos com o apoio do software Eudico Language Annotator (ELAN), denominação usada para identificar um recurso tecnológico desenvolvido pelo Instituto de Psicolinguística Max Planck, na Holanda, que permite a criação, edição, visualização e busca de anotações através de dados de vídeo e áudio. O software livre pode ser obtido em $<$ https://tla.mpi. $\mathrm{nl} /$ tools/tla-tools/elan/>. A escolha por esse software se deve a várias razões. Destacamos, entre elas, o fato de que ele permite a associação da transcrição e de quaisquer outras anotações que o pesquisador julgar 
necessárias a trechos dos vídeos, o que contribui para a representação do fato enunciativo. Isso porque o recurso audiovisual permite recuperar, ao menos em parte, o ato de enunciação, o qual é revivido pelo pesquisador, ao mesmo tempo em que é apresentada a sua interpretação para os fatos enunciativos eleitos para análise, por meio da transcrição pelo registro escrito e das anotações de comentários já indicativos de uma análise a se realizar ou que já se realiza no ato de transcrição.

\section{Recorte enunciativo 1}

Participantes: Dália, Mar e Ber

Data da coleta: 28/10/2012

Idade da criança: $2 ; 5 ; 4$

Situação: Dália e Mar caminham no pátio observando um gato de cor amarela que passeia entre elas.

Dália OLHA ! o pintinho amaleelinho... não. espera. não i fica qui.

comentário Dália fala dirigindo-se ao gato que passa por ela.

Dália não é a maluca. é o pintinho... oi... ... vem vem vem

Dália olha o pintinho amalelinho

Mar CUIDADO. ele é UM PINTIINHO amarelinho??

Dália ééé ... vem PINtiiinhuu ... o que o pinTInho tá fazeenndo?

Mar ele não é um gatinhoo?

Dália ele é gatinhoo miaaauuu oi gatiin/gatinho

Mar por que tu chama ele de pintinho?

Dália chama eele ... PINTINHOO... GATINHOOO.... PINTINHOOO gatinhopintinho

comentário Mar ri baixinho.

Mar

o nome dele é gatinho pintinho amarelinho?

Dália vaivai... vai lá na água

corpo Movimenta o braço fazendo sinal para o gato ir em frente.

Dália olha o gatinho ama/lelinho... é é PINtinho amalelinho? 
Mar é pintinho amareLInho? ... igual o da música né?... vamo cantá PRA ELE?

Dália vaamu

Mar como é que é?

corpo Dália faz o movimento de bater um dedinho na palma da mão, silenciosamente, numa referência à mímica da música infantil.

Mar caabe aqui ?

Dália na minha mão

Mar QUEM que cabe na tua mão?

Dália o piintinho

Mar o pintinho amarelinho? e dá pra cantá uuum gatiinhoo amareliiinho... dá?

comentário Mar enuncia o trecho da música infantil cantarolando-o.

corpo Dália corre, distraindo-se com a visão de Ber que se aproxima.

\section{Recorte enunciativo 2}

Participantes: Dália, Ber e Mat

Data da coleta: $28 / 10 / 2012$

Idade da criança: $2 ; 5 ; 4$

Situação: Dália, Ber e Mar voltam a atenção para uma gata doméstica que entra no quiosque onde eles se encontram.

Mar chÃchÃ SAI PRÁ LÁÁÁ MAROTA. MAROTA NÉ Dáália !?

Dália MAIOOOTA MAA-ROO-TAAA

corpo

Volta-se para a gata ao falar.

Ber maarootAAA

comentário Ber enuncia a palavra com musicalidade, cantando-a.

Dália marootaa marootaa 
comentário Dália também procura impor um ritmo musical ao dizer Dália di vem

corpo Dália corre, fugindo da gata

Ber CARA DITATU

Dália CATUTUUU catutuuu catu

corpo caminha atrás do gato

comentário Dália procura captar o enunciado de Ber e enuncia cantarolando

Nesses recortes enunciativos, foi usado um cabeçalho descritivo com informações contextuais que visam a situar o fato enunciativo na situação em que ele ocorreu: os participantes da situação de comunicação expressa no recorte, por meio da citação de seus nomes ou iniciais de seus nomes ou funções que desempenham na relação afetiva; a data da coleta do fato enunciativo; a idade da criança no momento da coleta; uma breve descrição da situação na qual a criança se encontrava quando a coleta foi realizada. Nos registros das falas da criança e dos demais participantes, foi tomada uma decisão extremamente pontual e significativa para os fins da pesquisa mencionada: o pesquisador transcritor optou por não usar letra maiúscula no registro dos nomes próprios, porque a letra maiúscula representa, na transcrição em foco, tons ascendentes. A letra maiúscula, assim, foi usada para os nomes próprios apenas na trilha "comentários" e na trilha "corpo".

Outra escolha que afeta a transcrição diz respeito à noção de recorte enunciativo, concebido por nós como o espaço de discurso em que determinado sentido é mobilizado por meio de determinados procedimentos na relação eu-tu. A configuração de cada um desses recortes é decisão do pesquisador, baseada nos objetivos da pesquisa. Sendo assim, entendemos que o recorte enunciativo precisa interrogar o pesquisador e, ao mesmo tempo, dizer-lhe algo sobre as especificidades da realização vocal na experiência da criança na linguagem.

No caso da pesquisa em foco, em especial, no caso dos dois recortes citados, podemos afirmar que há um esforço do pesquisador transcritor em registrar as operações reveladas por meio da mobilização 
dos arranjos vocais, uma vez que este é o tema ao qual a referida pesquisa se dedica. Nessas operações, os elementos linguísticos recebem uma espécie de contorno de sentido pela mobilização do vocal, o qual só pode ser compreendido na integralidade do ato enunciativo. $\mathrm{O}$ recorte enunciativo 1 congrega muitos arranjos vocais que contribuem para ilustrar o que estamos focalizando aqui: a criança, na relação intersubjetiva com o adulto, ajusta forma e sentido em sua enunciação. Nesse ajuste, há o papel de um elemento da cultura que marca o diálogo em questão: a concorrência entre a palavra "pintinho" e "gatinho" só é vivenciada em função do arranjo vocal que dá conta do ritmo da música infantil para o qual as duas formas são satisfatórias, independentes do que significam. Nesse jogo de apropriações, a criança mobiliza, sempre na relação intersubjetiva constitutiva da enunciação, arranjos vocais que buscam "afunilar sentidos". No discurso, portanto, na semantização, no ato de converter os signos em palavras, concorrem para a mobilização do sentido na instância enunciativa, os arranjos vocais específicos que garantem ao discurso o estatuto de música, estabelecendo no enunciado a sintagmatização dos elementos segmentáveis, como são os fonemas, as palavras e, em destaque, o sintagma "um gatinho amarelinho". Nessa situação, o sentido é mobilizado muito mais pelos arranjos vocais do que por uma ou outra unidade de um nível linguístico. Ao concorrer com as duas formas em relação associativa para constituir seu discurso, a criança mobiliza propriedades de dissociação e de integração das unidades linguísticas, atualizando-as, por meio do ritmo musicado, na singularidade da enunciação. É, portanto, papel do pesquisador transcritor registrar esses movimentos discursivos em sua transcrição, o que o leva a fazer escolhas de registro sempre renovadas e que o impelem, muitas vezes, a explicitar informações dos fatos de linguagem vivenciados por meio de recursos descritivos, verificados nas trilhas corpo e comentário. O sentido mobilizado, assim, no discurso analisado, não pode ser captado apenas pelo registro dos elementos verbais, havendo a necessidade de inserção de tais trilhas, o que relacionamos com a ideia anteriormente apresentada de tentativa de recuperação de perda, característica de toda enunciação, decorrente da efemeridade do discurso. É uma tentativa de recuperar a instância enunciativa que leva o transcritor a registrar, por exemplo, a seguinte informação, no recorte 1: "Mar ri baixinho". Esse registro, entre outros, revela a necessidade de o pesquisador transcritor apreender a realidade em que se realiza o ato enunciativo, uma vez 
que é a partir da noção de referência a essa realidade que o sentido é mobilizado no discurso.

Além disso, os arranjos vocais constituem novas formas e sentidos na particularidade do discurso, evocando elementos dos esquemas sociais vivenciados pela criança. $\mathrm{O}$ registro dessa evocação só é possível via gesto interpretativo do pesquisador transcritor, resultado da relação de interpretância revelada na mobilização da língua. conforme observamos na trilha corpo do recorte 1: "Dália faz o movimento de bater um dedinho na palma da mão, silenciosamente, numa referência à mímica da música infantil". É por meio da descrição do gesto da criança, constitutivo do seu dizer, que o sentido se particulariza no ato de transcrição.

É importante destacar o papel do outro da enunciação nesse ajuste de formas e sentidos: ainda no recorte 1, o adulto interroga a criança acerca da propriedade do uso da forma "pintinho" e o faz principalmente a partir de tons ascendentes e entonação bastante marcada de interrogação. Devido à insistência do outro, a criança resolve a questão alternando as formas "gatinho" e "pintinho" na busca de referência e correferência que atenda à relação intersubjetiva necessária para que a enunciação/coenunciação aconteça. Sendo assim, a criança se apropria do sistema de substituição e de integração de unidades da língua na mobilização de sentidos particulares. Esse sistema, portanto, é afetado pela relação singular que marca a emissão e a percepção dos sons da língua, na vivência da "diversidade das situações nas quais a enunciação é produzida" (BENVENISTE, 1970/1989, p. 83). Por essa razão, não seria possível a investigação dos elementos propostos na pesquisa se o registro do transcritor recaísse apenas nas formas mobilizadas pela criança. $\mathrm{O}$ sentido mobilizado no discurso implica, portanto, que o trabalho de transcrição se ocupe da relação estabelecida pela língua mobilizada na enunciação entre o eu e o $t u$. Justamente por isso percebemos nos recortes 1 e 2 um investimento do transcritor nessa relação, o que se dá por meio da descrição de elementos contextuais presentes na trilha comentário, como evidenciamos no recorte 2: "Dália procura captar o enunciado de Ber e enuncia cantarolando". A descrição apresentada revela a interpretância manifestada linguisticamente pelo transcritor em relação ao ato enunciativo vivenciado pela criança e pelo outro.

Nesses recortes, foram usadas as seguintes normas de transcrição, pensadas para o fim específico da pesquisa cujo foco se centrava nos arranjos vocais mobilizados na enunciação pela criança. 


\section{QUADRO1}

Normas de transcrição

\begin{tabular}{|c|c|}
\hline Procedimentos & Recursos de registro \\
\hline Tons ascendentes & Letras maiúsculas \\
\hline Tons descendentes & Sublinhado \\
\hline Entonação de interrogação & Ponto de interrogação? \\
\hline Entonação de exclamação & Ponto de exclamação! \\
\hline Alongamentos & Repetição da letra representativa do som alongado \\
\hline $\begin{array}{l}\text { Pausas breves, com duração de até } \\
3 \text { segundos }\end{array}$ & - \\
\hline $\begin{array}{l}\text { Pausas longas, com duração de } \\
\text { mais de } 3 \text { segundos }\end{array}$ & $\cdots \cdots$ \\
\hline $\begin{array}{l}\text { Gesticulação, movimentos } \\
\text { corporais e faciais da criança }\end{array}$ & $\begin{array}{l}\text { Comentários descritivos do pesquisador em trilha } \\
\text { específica para esse fim denominada "corpo" e } \\
\text { relacionada à trilha da enunciação com a qual há } \\
\text { concomitância com o sinal : } \\
\text { Quando o sinal : não é usado, trata-se de gesticulação, } \\
\text { movimentos corporais e faciais da criança realizados } \\
\text { na sequência em que aparecem na transcrição, não } \\
\text { concomitantes ao enunciado. }\end{array}$ \\
\hline $\begin{array}{l}\text { Concomitância entre a } \\
\text { gesticulação, movimentos } \\
\text { faciais e corporais e o enunciado } \\
\text { verbalizado }\end{array}$ & :::::: \\
\hline Interrupções bruscas do enunciado & 1 \\
\hline Sobreposição de vozes & {[} \\
\hline Silabação & - (sílabas separadas por hífen) \\
\hline $\begin{array}{l}\text { Entonação de fechamento de } \\
\text { frase, marcada somente quando a } \\
\text { situação exigir a explicitação de } \\
\text { tal entonação na interpretação dos } \\
\text { fatos }\end{array}$ & Ponto final \\
\hline Comentários contextualizadores & $\begin{array}{l}\text { Comentários descritivos do pesquisador, em trilha } \\
\text { específica para esse fim denominada “comentários”, } \\
\text { em relação ao aqui-agora da enunciação que não } \\
\text { envolvem gesticulação, movimentos corporais e } \\
\text { faciais da criança }\end{array}$ \\
\hline
\end{tabular}

Fonte: DIEDRICH, 2015. 
Apresentamos o quadro de normas apenas para fins de elucidação das escolhas realizadas pelo transcritor na pesquisa referida como ilustração. É importante também que apresentemos a relação dos aspectos focalizados neste artigo com o quadro em questão. $\mathrm{O}$ primeiro aspecto que se revela em nossa reflexão diz respeito às especificidades advindas da realização vocal da linguagem. A esse respeito, Flores e Surreaux (2012) lembram os estudos de Barbosa (2010), segundo os quais, as funções linguísticas do ritmo e da entonação encontram lugar na perspectiva linguística enquanto fenômenos linguageiros e comunicativos; os marcadores discursivos, atitudes, emoções e fenômenos ligados a fatores sociais e individuais teriam lugar nos estudos extralinguísticos e paralinguísticos. Flores e Surreaux (2012, p. 91) apontam para a possibilidade de se verem os fenômenos entendidos por Barbosa como extralinguísticos e paralinguísticos de outra forma, numa "perspectiva linguística - mesmo que não a clássica - entendida de um ponto de vista enunciativo". Assim, os elementos decorrentes da realização vocal da língua na enunciação são vistos como constitutivos do ato de enunciação, uma vez que "estabelecem uma sintagmática na enunciação dos elementos segmentais, uma espécie de concatenação entre eles" (FLORES; SURREAUX, 2012, p. 87). Essas especificidades convergem para um olhar transversal em relação à enunciação, o qual verá cada unidade linguística mobilizada em relação ao todo do discurso. É justamente esse olhar transversal que deve perpassar todo o ato de transcrição. Salientamos que a marcação dos fenômenos discursivos encontra sua razão de ser na análise qualitativa que geralmente caracteriza pesquisas gerenciadas pela abordagem enunciativa aquisicional. Logo, a marcação dos fenômenos é extremamente importante para a análise, pois o pesquisador nela se pauta para analisar a mobilização de sentidos particulares em cada ato enunciativo. Além disso, cabe destacar que, como não se elegem elementos a priori para investigação, os comentários do transcritor, como o que se encontra na percepção do vocal, acabam por trazer elementos importantes para a análise, nesse ato de interpretância do transcritor, conforme já discutido neste artigo.

Tal realidade nos conduz à outra especificidade do tratamento dos arranjos vocais: trata-se da relação de emissão e percepção definidora das marcas de transcrição a serem adotadas: o pesquisador transcritor assume seu papel de escuta e, a partir desse papel, é que define o que marcar e o que não marcar na transcrição. Apesar de os elementos a 
serem analisados não serem definidos a priori nas pesquisas realizadas na perspectiva da enunciação, há um gesto de interrogação prévio ao ato enunciativo de registro da transcrição. Esse gesto de interrogação é que norteia a definição das marcas usadas na transcrição. Portanto, numa investigação cuja metodologia envolve a transcrição de fatos de linguagem, vivem-se dois momentos distintos na história da pesquisa: um antes do registro, em que o pesquisador adquire intimidade com o corpus a partir da interrogação dos fatos de linguagem nele revelados; e um outro, o do registro. A relação de interpretância dos fatos, portanto, não ocorre no ato de registro; há o momento anterior, de escuta, ao qual em geral não se faz referência, mas que se encontra implícito em toda pesquisa. É sabido que todo pesquisador, frente aos fatos de linguagem a serem transcritos, investe grande esforço e muito tempo para a realização desta etapa de escuta, a qual é decisiva para a transcrição. Logo, quando, numa perspectiva enunciativa, afirma-se que os fatos a serem analisados não são definidos anteriormente, quer-se dizer, na verdade, que esses fatos se revelam durante a pesquisa, a qual envolve o momento de escuta do pesquisador. E é justamente e tão somente em razão dessa relação temporal que é possível, numa pesquisa de abordagem enunciativa, trabalhar-se com um quadro de normas de transcrição, como o que apresentamos.

Relacionamos essa constatação ao princípio proposto por Benveniste e já referido por nós: "Aquele que fala faz renascer pelo seu discurso o acontecimento e a sua experiência do acontecimento. Aquele que o ouve apreende primeiro o discurso e através desse discurso, o acontecimento reproduzido." (BENVENISTE, 1963/2005, p. 26). Para o autor, "renascer" refere-se ao fato de a realidade vivenciada ser produzida novamente, mas submetida à organização da linguagem. Há uma função mediadora da língua na reprodução dos acontecimentos vividos. Por meio desse propósito, realiza-se o caráter da linguagem definido por Benveniste (1952/2005, p. 65): "propiciar um substituto da experiência que seja adequado para ser transmitido sem fim no tempo e no espaço". Ao se apropriar dos fatos da experiência da criança na linguagem, o pesquisador busca simbolizar, por meio da transcrição, sua própria vivência interpretativa de tal experiência, instanciando-se, por meio das escolhas das marcas de transcrição no aqui-agora da enunciação.

Ao analisar os arranjos vocais nessa experiência, é importante, numa abordagem enunciativa, lembrar que "os mesmos sons não são 
jamais repetidos exatamente", sendo a identidade apenas aproximativa, "mesmo quando a experiência é repetida em detalhe" (BENVENISTE, 1970/1989, p. 83). O que estamos focalizando é justamente a reprodução, por meio do discurso, da experiência na linguagem vivida em determinado evento social. Destacamos o uso do prefixo "re" em "reproduz", uma vez que ele aponta para o fato de que, embora as formas linguísticas sejam as mesmas, elas se revestem, a cada enunciação, de características renovadas, próprias de cada ato enunciativo, conforme raciocínio de Dessons (2006). Trata-se da "experiência repetida em detalhe" a que se refere Benveniste e que permite que visualizemos a dupla natureza da língua: social, manifestada nos esquemas culturais que determinam a mobilização dos arranjos vocais; individual, manifestada nas escolhas particulares da criança a cada ato e que constituem os arranjos vocais específicos observados em cada situação e que dependem da relação de emissão e de percepção vivenciada a cada vez que a língua é mobilizada em atos enunciativos.

Outro aspecto em torno do qual refletimos é a necessidade de se marcar na escrita fenômenos da oralidade. Segundo Silva (2012, p. 355), "se torna impossível dar conta de 'tudo' que se apresenta na oralidade em sua representação escrita". Nem tudo, portanto, pode ser registrado nesta transposição da oralidade para a escrita, uma vez que há uma perda, consequência do próprio ato de enunciação que se realiza no aqui e no agora da própria enunciação. $\mathrm{O}$ que cabe ao pesquisador transcritor é tão somente uma tentativa de recuperação desse ato que se perde na efemeridade de sua realização. $\mathrm{Na}$ busca de registro dos arranjos vocais específicos que constituem o dizer da criança e do outro da enunciação, o quadro de normas recorre a recursos da escrita como tentativa de captar o oral, conforme verificamos no uso de letras maiúsculas e no sublinhado para marcação da entonação ascendente e descendente, respectivamente; no uso da repetição de vogais para marcar os alongamentos vocálicos; e dos pontos de interrogação e exclamação na busca de marcação das entonações interrogativas e exclamativas, respectivamente.

Tal tentativa é também expressa na definição de uso da trilha comentários. Nessa trilha, verifica-se mais explicitamente do que nas demais a subjetividade do pesquisador transcritor, já referida por Hilgert (1989). Isso porque o pesquisador transcritor realiza "propósitos significantes sobre a significância", segundo Benveniste (1969/1989, p. 66). Ou seja, ele se vale da língua para interpretar a própria língua: o 
pesquisador transcritor enuncia, à sua maneira, a interpretação que faz do fato enunciativo que marca os recortes de análise.

O quadro de normas também contempla a trilha corpo, uma vez que o gesto constitutivo do dizer é levado em consideração na análise enunciativa, o que motivou a definição de tal marcação na transcrição. Acerca disso, lembramos Cavalcante e Brandão (2012), em trabalho acerca da gesticulação e fluência em aquisição da linguagem: as autoras focalizam a relação da fala com recursos expressivos advindos da gestualidade, dos movimentos corporais e da mímica. Por essa razão, as autoras entendem a fala como multimodal. Com seus estudos, elas têm mapeado a emergência dos gestos na primeira infância, considerando a produção de fala em situações dialógicas.

A necessidade de registro da descrição dos gestos da criança no ato enunciativo nos leva a pensar novamente na ideia de perda, de resto, já referida anteriormente. Isso porque tais descrições colocam em evidência aspectos gestuais da criança considerados importantes e necessários para análise do ponto de vista do pesquisador transcritor, enquanto outros aspectos de mesma natureza talvez nem tenham sido percebidos por ele e, portanto, não são revelados na trilha. Há, portanto, uma escolha por parte do pesquisador do gesto considerado relevante naquele ato enunciativo. Além disso, nem todas as enunciações das crianças recebem acompanhamento da trilha corpo na transcrição. Será porque, de fato, não foram marcadas por gestos constitutivos do dizer ou será porque o pesquisador transcritor julgou não ser necessária esta marcação para os fins de sua pesquisa? As decisões do pesquisador transcritor funcionam assim como uma espécie de filtro entre os fatos que marcam o ato de enunciação em si e os fatos eleitos para análise em função dos objetivos da pesquisa. O que se tem, dessa forma, na transcrição, é o ato interpretativo do pesquisador transcritor, o que funda uma nova enunciação derivada da relação de interpretância por ele vivida.

Ainda em relação a esse mesmo aspecto, verificamos que, na trilha comentário, cujo conteúdo recai sobre a situação enunciativa em si, na o pesquisador transcritor busca descrever o aqui e o agora em que se realizam os fatos a serem analisados. Novamente, a relação é de seleção do que é relevante ser descrito para os fins de análise propostos. Há, na constituição dessa trilha, novamente, a explicitação do ato interpretativo do pesquisador transcritor, porque ele assume o papel de descritor, cumprindo o que Normand (2009, p. 181) diz acerca desse trabalho: o 
estudo enunciativo "depende menos de uma análise linguística do que de um comentário de texto cada vez particular". A que tipo de comentário se refere Normand? Segundo a autora, esse comentário se apoia na descrição semiótica, a dos marcadores da enunciação, pertencentes ao sistema da língua, mas com a propriedade específica de atualização no aqui-agora da enunciação. É dessa atualização que o pesquisador se apropria e, por sua vez, também empreende sua atualização sobre os fatos analisados, caracterizando sua transcrição como um novo ato enunciativo.

Acerca dessa experiência, lembramos o raciocínio benvenistiano apresentado em Estruturalismo e linguística (1968/1989, p. 20-21), segundo o qual a criança, ao aprender uma língua, aprende o mundo do homem: "A apropriação da linguagem pelo homem é a apropriação da linguagem pelo conjunto de dados que se considera que ela traduz." Sendo assim, se é papel do pesquisador entender a apropriação da linguagem pela criança, precisará explicitar o conjunto de dados que essa experiência traduz, os quais se confundem com a constituição do homem no meio cultural de que faz parte, caracterizado pelo conjunto de valores que se articulam e se dão a conhecer no simbólico da linguagem, realizando-se, assim, a tríade homem, linguagem e cultura. Trata-se do seguinte princípio a ser levado em conta em pesquisas cujo foco de interesse sejam as realizações vocais da criança: as vocalizações evocam valores culturais impressos no discurso do outro, os quais possibilitam a experiência singular da criança na linguagem.

Esse princípio nos leva à noção de "semantismo social", conforme discorre Benveniste (1968/1989) em Estrutura da lingua e estrutura da sociedade. $\mathrm{O}$ autor, ao discutir as relações entre língua e sociedade, afirma que "a língua interpreta a sociedade. A sociedade torna-se significante na e pela língua, a sociedade é o interpretado por excelência" (BENVENISTE, 1968/1989, p. 98). A partir dessa ideia, entendemos que toda a organização da vida em sociedade, para ser compreendida, precisa do seu interpretante, que é a língua. Assim, o "semantismo social" está relacionado aos valores culturais impressos na realização vocal da língua na enunciação. Ao falar, portanto, o homem não apenas mobiliza formas e sentidos particulares explicitados na língua da qual se apropria, ele vai além, comunica, pela mobilização de arranjos vocais, valores sociais, capazes de revelar muito acerca da sua história construída no seio de uma sociedade e da experiência por ele vivida no mundo que o cerca. Para nós, o conceito de cultura está relacionado ao sistema de valores, 
uma vez que na experiência da criança na linguagem vemos a realização vocal manifestar rudimentos da cultura, pois a criança entra no mundo do outro, o mundo do adulto, sai da liberdade da pura natureza para experenciar os limites simbólicos da cultura que a cerca.

Encontram-se nos arranjos vocais mobilizados pelo outro em relação à criança uma série de elementos decorrentes do sistema de valores que caracteriza a vida em sociedade, a saber: para certa situação social, por exemplo, a criança vivencia uma forma de mobilização da realização vocal: entonação descendente, sussurro, entre outras. Há, portanto, um semantismo social que se revela nos arranjos vocais. Assim, ao se valer de tais arranjos em suas enunciações, o locutor marca sentidos que estão relacionados às suas emoções, às relações familiares, aos elementos de ordem social, por exemplo. Na relação com o outro, a criança está sempre mobilizando sentidos particulares que encontram eco na cultura que a cerca. Para isso, o simbólico da língua é o elemento que restringe a mobilização do vocal na enunciação pela criança: ela não apenas "brinca" com a emissão fônica, mas se marca no discurso fazendo a passagem, por meio dos arranjos vocais, de locutor a sujeito.

Essa realidade é vivida pela criança desde que sua existência se confirma no mundo dos homens e a ela os adultos passam a se dirigir: a cada ato enunciativo, os valores culturais acima mencionados são revelados à criança e passam a constituir também a sua experiência na cultura. Para dar conta de todos esses fatores mobilizados via arranjos vocais na linguagem da criança, é fundamental que a transcrição vá além do dito, marcando, por meio de algum recurso, essa relação de dependência entre língua e valores culturais reveladas na enunciação.

Assim, o ato de transcrição envolve muito mais aspectos do que simplesmente decisões e escolhas de sinais de registros dos elementos vocais, ele se revela já uma etapa importante de análise dos fatos estudados, a qual exige que o pesquisador transcritor assuma a função de interpretar o dizer do outro, neste caso, da criança, inserida na cultura da qual faz parte, o que só lhe é possível a partir de princípios de significância que olhem para a vida da linguagem no seio da sociedade.

Pensar na linguagem e na transcrição de fatos da linguagem, implica, portanto, pensar na faculdade simbolizante da língua no seio da sociedade. Em Estrutura da língua e estrutura da sociedade, Benveniste (1968/1989) reafirma que não encontramos jamais linguagem separada de sociedade, apesar de essas entidades apresentarem estruturas diferentes. 
Nesse processo, a sociedade torna-se significante na e pela língua. Para tanto, a língua deve manter-se capaz de registrar, de designar e orientar as mudanças que caracterizam o interpretado, ou seja, a sociedade. Conforme Benveniste, a significância da língua se dá em relação a todos os demais sistemas significantes que constituem a cultura humana e que toda criança apreende, com a língua, os rudimentos da cultura.

É justamente a faculdade simbolizante que distingue o homem do animal e é a fonte comum do pensamento, da linguagem e da sociedade. Esse aparato simbólico possibilita a relação entre o homem e o mundo, entre os homens, estabelecendo-se, dessa forma, por meio da linguagem, a estrutura social, conforme afirma Benveniste (1963/2005, p. 31, grifo do autor):

[...] a linguagem se realiza sempre dentro de uma língua, de uma estrutura linguística definida e particular, inseparável de uma sociedade definida e particular. Língua e sociedade não se concebem uma sem a outra. Uma e outra são dadas. Mas também uma e outra são aprendidas pelo ser humano, que não lhes possui o conhecimento inato.

Logo, uma pesquisa que busque investigar a aquisição da linguagem numa perspectiva enunciativa precisa se desenvolver a partir do princípio de que a vida em sociedade, desde muito cedo, se constitui com a utilização de vários sistemas de signos: "Nossa vida inteira está presa em redes de signos que nos condicionam a ponto de não se poder suprimir apenas um sem colocar em perigo o equilíbrio da sociedade e do indivíduo". E nessa rede a língua exerce papel fundamental.

Essa dimensão semiológica traz à língua um novo estatuto, segundo o qual "somente a língua torna possível a sociedade" (BENVENISTE, 1969/1989, p. 63), pois, para o linguista, constitui o que mantém juntos os homens como fundamento das relações da sociedade. Por esse prisma, é possível dizer que é a língua que contém a sociedade.

Registrar, portanto, o mover da criança, via linguagem, nessa sociedade, é tarefa do pesquisador que se propõe a investigar a aquisição da linguagem, aspecto fundamental que interfere sobremaneira na transcrição dos fatos da linguagem por ele estudados, os quais jamais poderão ser vistos apenas como unidades de um nível linguístico ou de outro: fonemas, morfemas, elementos sintáticos. Acerca dessas limitações de descrições linguísticas pautadas no emprego das formas, também 
Benveniste ((1970/1989, p. 81) se posicionou, distinguindo esse emprego do emprego da língua. $\mathrm{O}$ autor faz isso afirmando ser essa distinção "uma outra maneira de ver as mesmas coisas, uma outra maneira de as descrever e de as interpretar". Essa afirmação do autor lança, aos nossos olhos, luzes sobre os fenômenos da aquisição da linguagem: os fenômenos estudados já podem ter sido analisados sob outros vieses, mas, seguindo o que propõe o linguista da enunciação, outras maneiras de descrever e interpretar tais fenômenos se apresentam quando se descortinam os aspectos da enunciação.

Ao fazer essa distinção entre emprego das formas e emprego da língua, o autor tece críticas ao grande número de modelos consequentes da descrição do emprego das formas, e o faz a partir da constatação de que "a diversidade das estruturas linguísticas não se deixa reduzir a um pequeno número de modelo" (BENVENISTE, 1970/1989, p. 82). Por isso, defende o estudo do emprego da língua, com ênfase naquele que realiza este emprego: o homem.

Feita a crítica aos modelos, o autor apresenta o que ele entende por emprego da língua: "Coisa bem diferente é o emprego da língua". E, para mostrar a diferença, define esse emprego como "um mecanismo total e constante que, de uma maneira ou de outra, afeta a língua inteira". Trata-se da enunciação: "este colocar em funcionamento a língua por um ato individual de utilização" (BENVENISTE, 1970/1989, p. 82). Destacamos nessa definição a ideia de ação, proposta pelo verbo "colocar" e confirmada em seguida pelo linguista (1970/1989, p. 82) quando afirma: "é o ato mesmo de produzir um enunciado, e não o texto do enunciado, que é nosso objeto. O locutor apropria-se do aparelho formal da língua e, nesse ato de apropriação, particulariza o emprego das formas a tal ponto que elas se configuram no aparelho formal da enunciação. No centro dessa vivência, está o funcionamento da língua, o que nos leva a refletir sobre o que, de fato, significa língua em funcionamento. Quando a língua funciona? Cremos que por "funcionamento da língua" estamos tratando, com Benveniste, da comunicação humana. Afinal, a língua existe para que os locutores possam constituir-se como protagonistas de sua comunicação. Mas o conceito de enunciação diz mais: "por um ato individual de utilização", o que nos leva a direcionar nosso olhar para as implicações de considerar-se a enunciação como um ato individual. Nos estudos da aquisição da linguagem, encontramos um histórico marcado pela definição de estágios e modelos no intuito de padronizar as etapas 
de aquisição. O que vemos com essa definição é bastante diferente: se entendemos a enunciação como um ato individual, as regularidades características da língua dão lugar às singularidades advindas da individualidade posta em cena na conversão da língua em discurso.

E é justamente o tratamento dessas singularidades que coloca o trabalho do pesquisador transcritor num patamar diferenciado quando assume uma perspectiva enunciativa aquisicional: depara-se com o novo a cada ato enunciativo, o que o leva a também renovar seu ato de transcrição a cada fato, a cada recorte.

\section{Para refletir}

Apresentamos aqui uma breve reflexão acerca do ato de transcrição como um ato enunciativo na busca do pesquisador em registrar os fatos de linguagem da criança, vistos como uma experiência de significação. Concluímos, com esse raciocínio, que o trabalho de transcrição de tais fatos envolve sempre a relação de interpretância da língua em relação aos fatos enunciados pela criança, relação esta que se dá por um ato interpretativo do pesquisador, o qual acaba, muitas vezes, por preencher lacunas na realização linguística da criança, cujas formas, em alguns momentos, ainda não se revelam coincidentes à estrutura linguística da qual o adulto já se apropriou; em outras vezes, o papel do transcritor envolve a decisão de definir o que é importante registrar e o que é dispensável para os fins anunciados em sua pesquisa. Por essa razão, entendemos que há uma especificidade no trabalho com fatos de linguagem dessa natureza, a qual exige um olhar singular para a metodologia de transcrição. Justamente por se tratar de um ato singular, a transcrição desses fatos é contemplada numa abordagem enunciativa aquisicional. Essa abordagem permite que se trabalhe com os fatos da linguagem da criança numa perspectiva que os vê como dependentes do aqui e do agora da enunciação, privilegiando aspectos singulares dos atos de fala, conforme Surreaux e Santos (2014); além disso, por se tratar de um olhar para a experiência de aquisição da linguagem, permite que se veja o mover da criança nessa experiência como a vivência de sua historicidade, com todas as lacunas e dissociações que isso possa representar quando comparada à vivência do homem adulto, na qual a língua já se presentificou de forma bem mais completa. Trabalhar com a transcrição dos fatos de linguagem da criança é, portanto, recuperar 
sua historicidade na experiência da significação ao se mover na e pela linguagem.

O papel de pesquisador da experiência da criança na linguagem realiza-se, dessa forma, por meio da vivência de sua própria experiência de dizer sobre o dizer dessa criança, o que, para nós, revela-se também como uma experiência de linguagem, manifestada nos atos de acompanhamento, transcrição e análise dos fatos enunciativos.

\section{Referências}

BENVENISTE, É. (1968). Estrutura da língua e estrutura da sociedade. In: . (1974). Problemas de Linguística Geral II. Campinas: Pontes, 1989.

BENVENISTE, É. (1969). Semiologia da língua. In: Problemas de Linguística Geral II. Campinas: Pontes, 1989. (1974).

BENVENISTE, É. (1970). O aparelho formal da enunciação. In: (1974). Problemas de Linguística Geral II. Campinas: Pontes, 1989.

CAVALCANTE, M. C. B.; BRANDÃO, L. Gesticulação e fuência: contribuições para o estudo da linguagem. Cadernos de Estudos Linguísticos. Campinas, p. 55-66, jan.-jun. 2012.

DIEDRICH, M. S. Aquisição da linguagem: o aspecto vocal da enunciação na experiência da criança na linguagem. 2015. 147 p. Tese de doutorado. Instituto de Letras. Universidade Federal do Rio Grande do Sul, 2015. Disponível em: <http://hdl.handle.net/10183/130026>.

DESSONS, Gérard. Émile Benveniste, l'invention du discours. Inpress, 2006.

ELAN. Disponível em: < https://tla.mpi.nl/tools/tla-tools/elan/>. Acesso em: 5 jan. 2016.

FLORES, V. Entre o dizer e o mostrar: a transcrição como modalidade da enunciação. ORGANON, Porto Alegre, n. 40/41, p. 61-75, 2006.

HILGERT, J. G. Língua falada e enunciação. Calidoscópio, São Leopoldo, v. 5, n. 2, p. 69-76, maio-ago. 2007.

NORMAND, C. Convite à linguística. São Paulo: Contexto, 2009. 
REY-DEBOVE, J. (1988). À procura de distinção oral/escrito. In: CATAH, Nina (Org.). Para uma teoria da língua escrita. São Paulo: Ática, 1996.

SILVA, C. L. da C. A criança na linguagem: enunciação e aquisição. Campinas, SP: Pontes, 2009.

SILVA, C. L. da C.; ENDRUWEIT, M. L. O oral e o escrito sob o viés enunciativo: reflexões metodológicas. ReVEL, v. 9, n. 16, 2011.

SILVA, C. L. da C.; SURREAUX, L. M. O tratamento do dado em aquisição e distúrbios de linguagem: uma leitura linguístico-enunciativa. Estudos em aquisição fonológica, Pelotas, v. 4, 2011.

SURREAUX, L.; SANTOS, R. O. Transcrição de base enunciativa em distúrbios afásicos: aspectos prosódicos e gestuais. Revista Prolíngua, v. 8, n. 2, 2014. 